\title{
A Before and After Analysis of the Impacts of the Inaguration of a New Metro Station in Naples
}

\author{
Francesca Pagliara ${ }^{*}$, , Claudio Troisi ${ }^{2}$ and Luca Pelliccia ${ }^{1}$ \\ ${ }^{I}$ Department of Civil, Architectural and Environmental Engineering -University of Naples Federico II, Italy \\ ${ }^{2}$ Department of Architecture -University of Naples Federico II, Italy
}

\begin{abstract}
In this paper a before and after analysis of the impacts of the inauguration of a new metro station in Garibaldi square in Naples in Italy will be presented. This station is part of Line 1 and it was inaugurated in January 2014. Moreover, many interventions have been carried out in Garibaldi square, surrounding the station. Therefore a reorganization of the whole transportation system connecting this new strategic node was necessary.

Two surveys have been undertaken with the objective of understanding these impacts. Indeed the first one aimed at identifying the present circulation scheme and the one induced by the inauguration of the station. The second one aimed at quantifying the entity of traffic flows in "critical points", by counting the vehicles during peak periods. From these surveys, it has come out that in the peak morning period (7am-10am) 6,000 vehicles have been counted towards the rail node Garibaldi. This value decreases of almost $15 \%$ in the afternoon peak period (12am-3pm) as well as in the evening one (5pm-8pm). A simulation model has been implemented as well in order to estimate future scenarios promoted by the local administration. Indeed the access to the square and to the surrounding areas (where the CBD and the historical centre are placed) changes completely
\end{abstract}

Keywords: Accessibility, before and after analysis, flows distribution, metro station.

\section{INTRODUCTION}

A decision process in transportation planning is made up of different macro-activities (see Fig. 1). In the right side of the figure the decision process is shown, while in the left side the phases of analysis and modeling functional to these activities are reported. In the phase of objectives and constraints identification, the objectives of the decisionmaker and the relevant constraints for the project are defined [1]. In the phase of analysis of the present situation, data on the transportation and activity systems are collected. This phase is also linked to the building of a mathematical model of the present system, since it provides the input data for the models (supply, demand, land-use). Furthermore it usually receives from the models estimates of system performance indicators such as flows, saturation levels, generalized transport costs by O-D pair. The next step is the formulation of system projects. Assessment and evaluation of alternative projects require the simulation of the relevant impacts of their realization.

After a project is implemented, one can compare forecasted and actual effects, observe the occurrence of unexpected developments and new problems, and evaluate social consent and/or dissent. These may modify some elements of the project or alter its future development. The

*Address correspondence to this author at the Department of Civil, Architectural and Environmental Engineering, University of Naples Federico II, Italy; Tel: +390817683932; Fax: +390817683946;

E-mail: fpagliar@unina.it monitoring of a project is the systematic checking of the main "state variables" of the transportation system and use of these checks for the identification of new problems and the a posteriori evaluation of project impacts.

The effects of any transport investment can be described in terms of the impacts relevant for some of the factors involved. Thus the definition of the relevant impacts is the main indicator of the approach followed and the breadth of the evaluation activity. The spectrum of the effects considered has widened with the passing of time in concert with improvements in modeling and simulation and with the expansion and classification of the different and often contrasting objectives and goals of actors and decisionmakers [1]. The impacts are considered for all users for the different transportation modes [2].

Impact indicators are typically computed for a subset of simulation or reference periods and then extrapolated to larger time periods. Many impacts can be simulated by using the models as shown in Fig. (2). The estimation of these impacts requires the simulation of the system in the project (P) and non-project (NP) states and the calculation of variations between the variables measuring quantifiable impacts.

Resources needed for construction, maintenance and operation and their relative costs can be estimated analytically from the actual design of facilities and services or, synthetically, using statistical relationships, known in the economic literature as production functions. Traffic revenues can be calculated by multiplying the number of users in the 


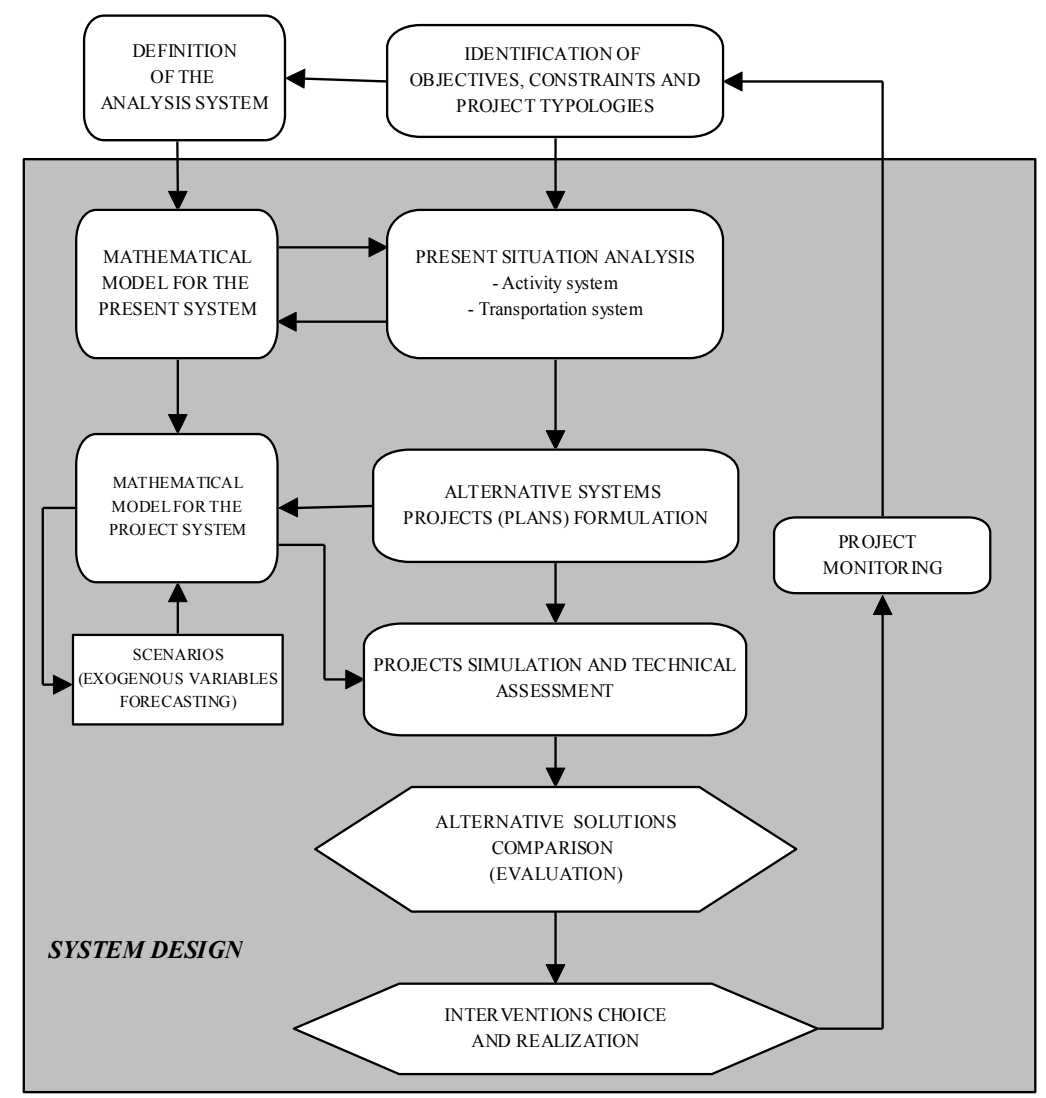

Fig. (1). Transportation systems design and the planning process [1].

simulation for tolled infrastructures and/or for transportation services for the relative prices.

Several other impacts can be calculated. For example, the probability of accidents and their consequences, fuel consumption, noise and air pollution can be evaluated through the relevant link impact functions. The ease of access to different services can be measured through accessibility variables deriving from destination choice models, or in other forms proposed in the literature.

In this paper the focus will be on a before and after analysis of the impacts of the inaguration of a new station of Line 1 of the metro in Naples in Campania region in the south of Italy, placed in Garibaldi square. Indeed the new metro station is named Garibaldi. The paper is organised as follows. In section 2 the case study of Line 1 of the metro station is described in the context of the metro lines in Naples. In section 3 the interventions proposed are reported and simulated. Section 4 reports the before and after analysis through the specification of some indicators.

\section{THE BACKGROUND}

Campania region is one of the twenty administrative regions making up Italy. It has about 5.7 million inhabitants and is the second largest region in Italy. It is made up of five administrative provinces and the large central metropolitan area is centred around Naples with 3.5 million inhabitants. During the second half of the last century, very limited investments were made to expand and/or upgrade the existing railway network. Furthermore, these efforts followed an un-coordinated process in which decisions were taken by individual transport companies, thereby limiting an integrated vision of the regional railway system. Moreover, expansion projects were not coordinated with decisions involving the land-use system. Indeed they were often made independently of the rail system. In 1996 the new planning approach started and it was extended in 2001 to the whole region with the Regional Metro System (RMS) project, which is is based on the principle that only an extended railway system can guarantee a sustainable mobility in this area [3].

Between 2001 and 2007 several interventions have been carried out on the urban rail network with the opening of new rail lines with the upgrading and opening of many stations both in central and peripheral areas of the city of Naples (see Table 1).

\subsection{The Metro System in Naples}

Line 1 of the metro in Naples covers the whole metropolitan area, thanks to the many connections with the rail system and park \& ride nodes placed in the north of the city. Indeed they foster the use of car with respect to the public system.

Line 1 connects the north of the city with the metro station of Piscinola/Scampia to the west and with Garibaldi station, which in turn connects the national railways with the High Speed Rail system [5], passing through the hilly area of the borough of Vomero and the old city center. It serves a total of 17 stations covering a distance of $18 \mathrm{~km}$. 


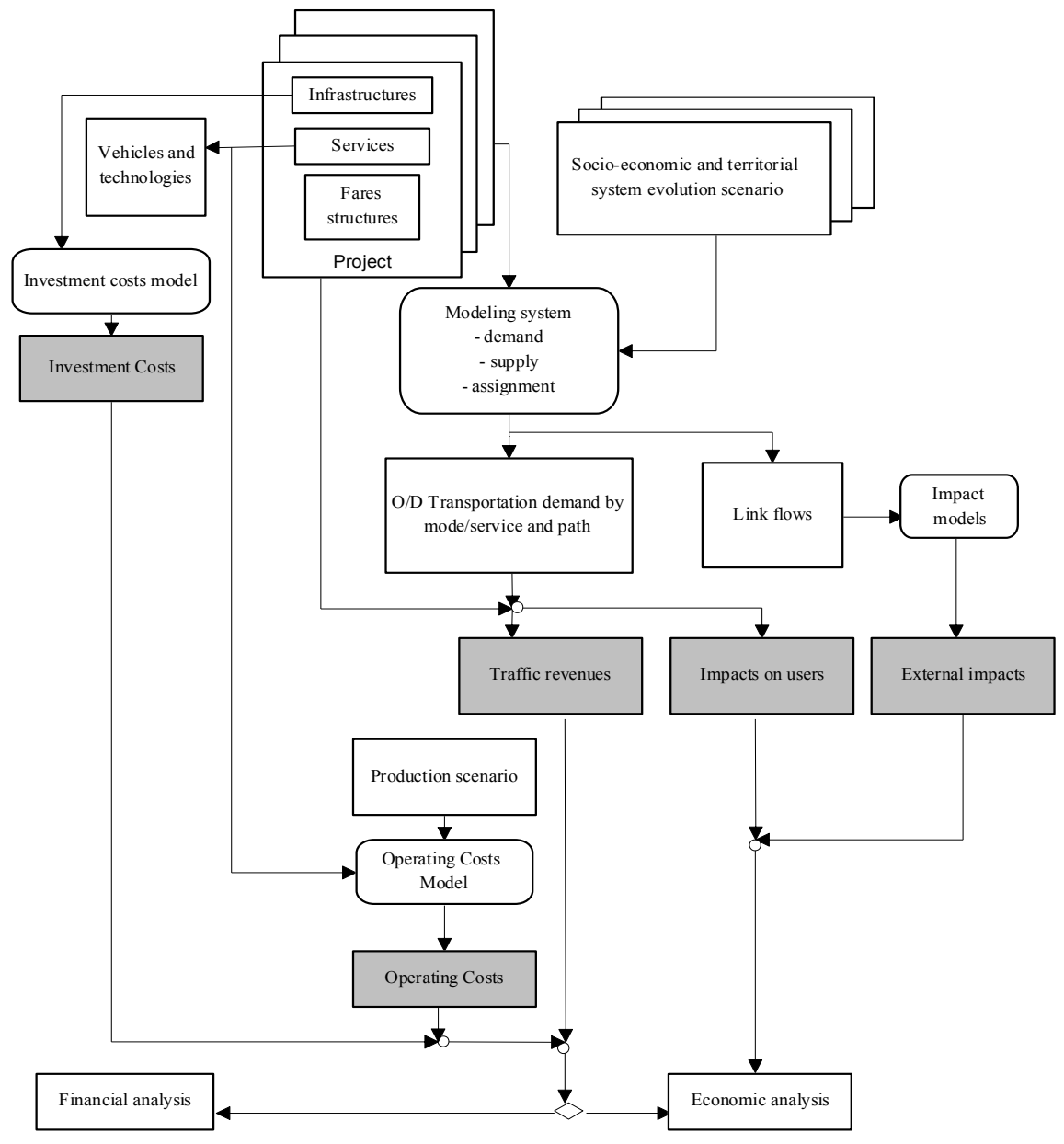

Fig. (2). Main components of an impact assessment process [1].

The stations have a total of 115 escalators, moving walkways, stair lifts and platform lifts and 52 elevators. Almost the entire route is developed in the gallery, except the stretch Colli Aminei/Piscinola, which runs mostly along the viaduct. The stations served are: Garibaldi, Università, Toledo, Dante, Museo, Materdei, Salvator Rosa, Quattro Giornate, Vanvitelli, Medaglie d'Oro, Montedonzelli, Rione Alto, Policlinico, Colli Aminei, Frullone, Chiaiano, Piscinola.
Line 1 operates on weekdays about 242 trips per day from 6:00 a.m. to 11:00 p.m., with a frequency, during peak hours, of 8 minutes. On average about 135,000 passengers use this service on weekdays and 50,000 on weekends (www.comunedinapoli.it).

The design and construction of Line 1 have been assigned to MN Metropolitana di Napoli SpA, a company of the Municipality of Naples, engaged for building the metro. The completion of the line involves the construction of a rail

Table 1. The RMS project infrastructures.

\begin{tabular}{|c|c|c|c|c|c|c|}
\hline & Base Scenario (2001) & Completed (2011) & Under Construction & Planned & Total & $\%$ Change \\
\hline Total extension of the railway network $(\mathrm{km})$ & 1,179 & 54 & 50 & 66 & 13,49 & $+14 \%$ \\
\hline Number of stations & 340 & 39 & 30 & 33 & 442 & $+30 \%$ \\
\hline Investments $(\mathrm{M} €)$ & - & 3,115 & 2,525 & 3,500 & 9,140 & \\
\hline
\end{tabular}

\begin{tabular}{|c|c|c|c|}
\hline & New & Revamped & Total New and Revamped \\
\hline \hline Number of trains & 94 & 75 & $\mathbf{1 6 9}$ \\
\hline Number of buses & 1,250 & - & $\mathbf{1 , 2 5 0}$ \\
\hline Total number of trains and buses & $\mathbf{1 , 3 4 4}$ & $\mathbf{7 5}$ & $\mathbf{1 , 4 1 9}$ \\
\hline
\end{tabular}




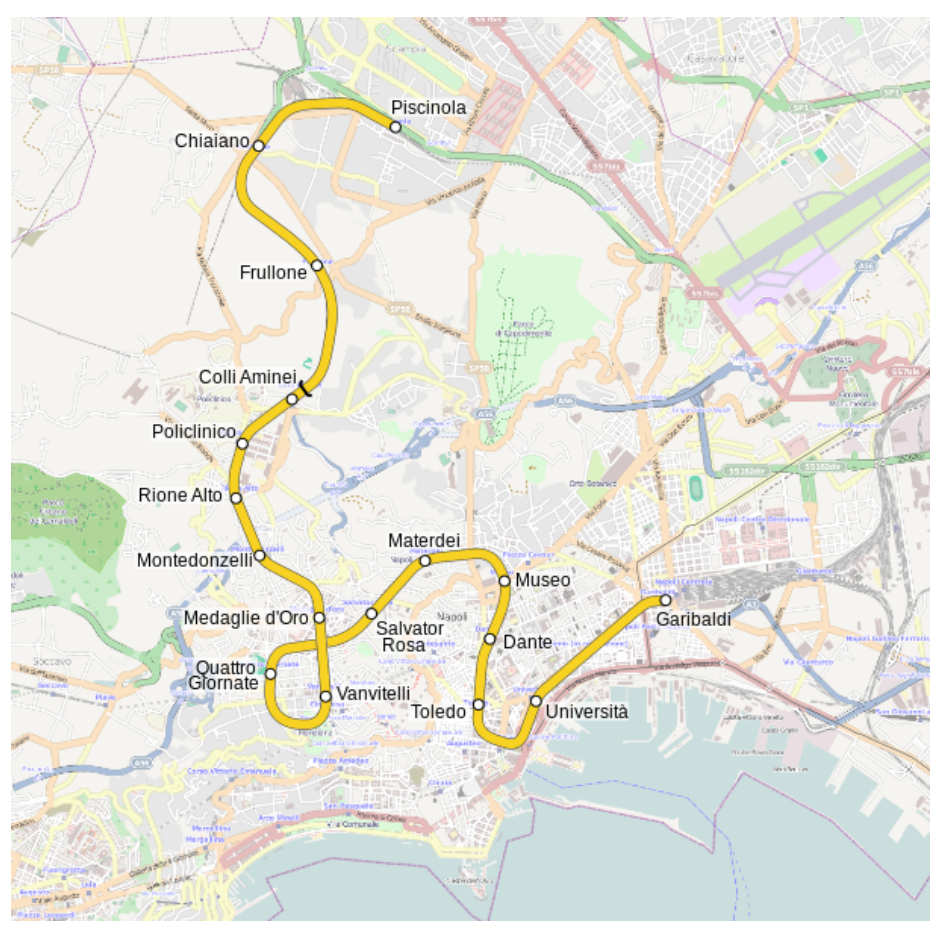

Fig. (3). Metro stations of line 1 in Naples. Source: www.metro.na.it.

link that will stop in Piscinola, passing the CBD and Capodichino airport. This intervention will contribute to the extension of the current route length (from $18 \mathrm{~km}$ to $25 \mathrm{~km}$ ). In Fig. (3), the metro stations of Line 1 are reported, while in Fig. (4) the future scenario is represented when all stations will be inaugurated.

Garibaldi square represents a strategic node in the present urban transportation system (see Fig. 5). From the public transport perspective, it is the most important interchange node between rail and road. The reasons are to be found in the number of facilities serving not only the metropolitan area, but also the regional and national demand incoming to the node. Specifically, the station Napoli Centrale, Garibaldi Square and Circumvesuviana (from 1980 till 2012, this was the company managing the urban and sub-urban rail systems in the metropolitan area of Naples, since 2012 this service has been managed by Ente Autonomo Volturno, in the common language people still call it "Circumvesuviana"), define an interchange node both internal and external to the transportation system of the city. Internal, since it links line 2 of Ferrovie dello Stato (The Italian National Railway) with the lines Naples-Sorrento, Naples-Sarno and Naples-NolaBaiano of the Circumvesuviana.

The presence of a bus terminal both at urban and extraurban level makes this node more attractive. From the private transport perspective, Garibaldi Square represents the only crossing node for flows coming from the coast and directed to north. However this node this node also "receives" the flows from the motorways A1 and A3.

\section{THE CASE STUDY}

Private and public transport needed to be re-organized after the inauguration of the new station with the objective of making mobility sustainable.
Two surveys have been undertaken. The first one aimed at identifying the present circulation scheme and the one induced by the inauguration of the station, and the other one aimed at quantifying the entity of traffic flows in "critical points", by counting the vehicles during peak periods.

Subsequently, a GIS software has been used to modify some nodes and links, with the support of a graph. Moreover a macrosimulation software has been considered for modifying nodes and links in order to understand the distribution of flows and the corresponding level of congestion in the area interested by the intervention. Finally, a micro-simulation model has been built as well, based on a Deterministic User Equilibrium assignment approach chosen for better interpreting users' behaviour on the road.

The first survey was carried out during the month of February 2014 (on the $5^{\text {th }}$ and the $6^{\text {th }}$ ) and during the morning and afternoon peak periods (i.e. 7:00-10:00am; 12:00-15:00pm and from 17:00-20:00pm) with the objective of analyzing the present scenario of the vehicles crossing Garibaldi Square in order to highlight the critical points w.r.t. the data of 2012. This information was used to calibrate and therefore simulate traffic flows through the software MT-Model (version: V4.1.010).

The activities which carried out were:

- Identification of the present circulation scheme of both the private and public transport networks.

- $\quad$ Flows of cars, buses, motorbikes crossing the square.

The main outcome has been that in the peak morning period (7:00am-10:00 am) 6,000 vehicles have been counted incoming to the rail node of Garibaldi. This value decreases of almost $15 \%$ in the afternoon peak period (12:00am$3: 00 \mathrm{pm})$ as well as in the evening one $(5: 00 \mathrm{pm}-8: 00 \mathrm{pm})$. 


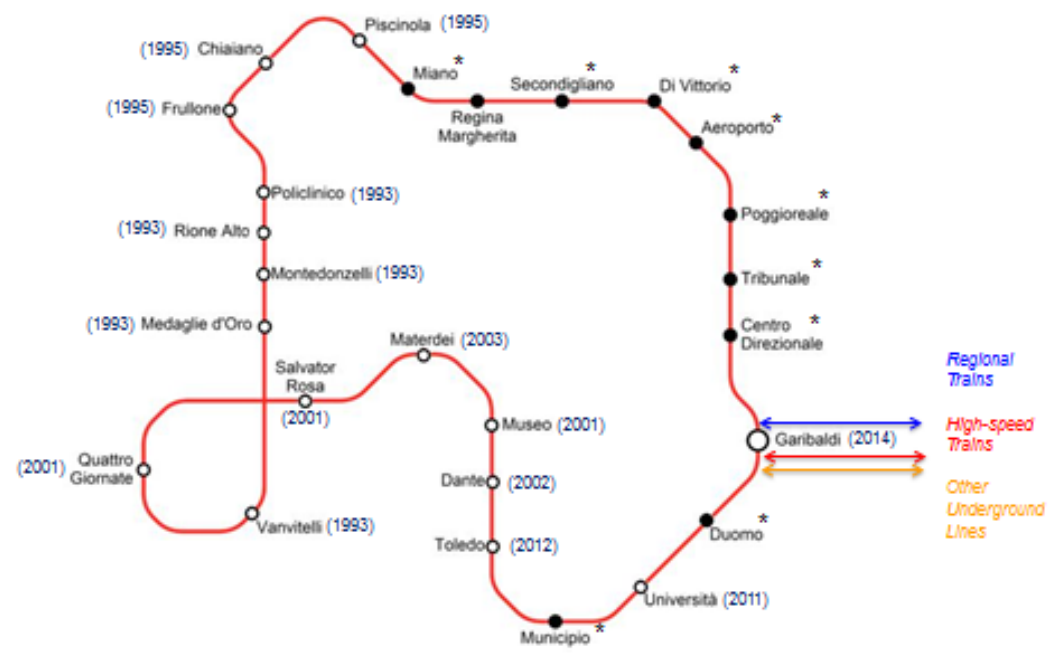

- status: under construction,

Fig. (4). The future scenario of line 1. Source: Authors' elaboration.
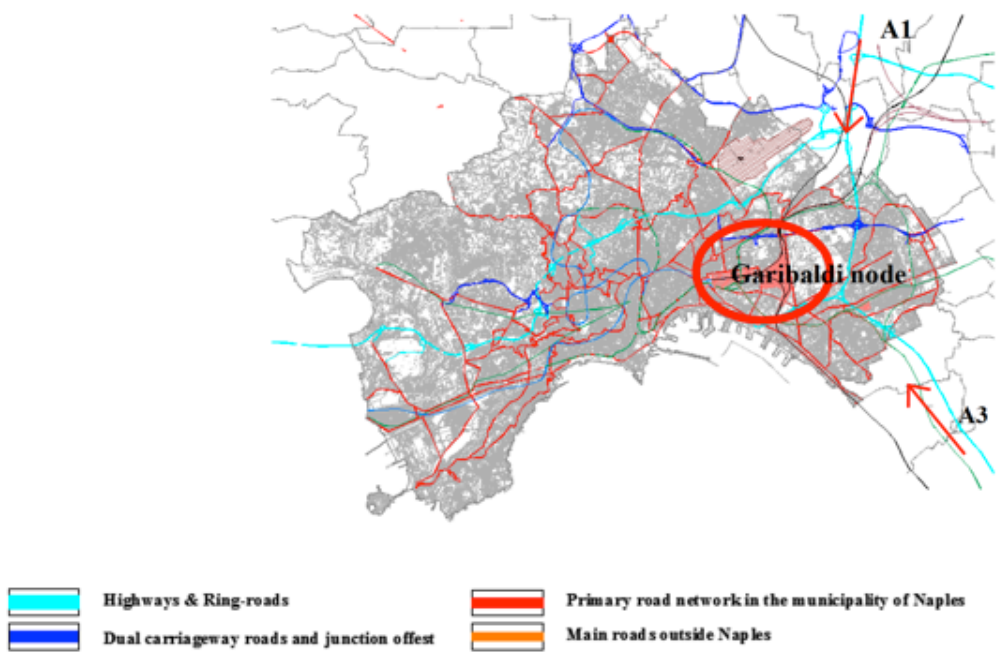

Primany road network in the municipa lity of Naples
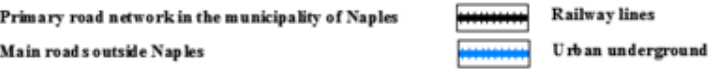

Fig. (5). Garibaldi node. Source: Authors' elaboration.

In Fig. (6) the distribution of flows by typology is reported, referring to all the periods during which the counts were carried out.

Future scenarios were simulated as well. They change radically, both from an infrastructural and functional point of view, the access to Garibaldi Square and to the surrounding areas (where the CBD and the historical centre are placed).. A new distribution of the vehicles has been registered with a decrease of the flows incoming from the motorway A3 of more than $20 \%$ and incoming to Garibaldi square of more than $30 \%$.

Fig. (7) refers to September 2012, before the inauguration of Garibaldi station, from there it is clear that it exists a high level of congestion incoming to the square due to the high pedestrian and car flows.

In Fig. (8) the same situation is reported but referring to December 2013, where some changes were carried out in order to make the circulation in this node more sustainable. Fig. (8) represents the actual scenario w.r.t Fig. (7), cars are not allowed to cross the square from north to south with the excpetion of buses, taxis and vehicles for loading and unloading freight. Finally, in Fig. (9) the future scenario has been implemented and simulated. The area becomes a traffic limited zone where only public transport is allowed to cross and two underpasses (circled in red) have been introduced as well.

It is possible to observe that the level of congestion, represented by the ratio between flow and capacity decreases.

\section{CONCLUSION}

In order to evaluate the impacts of the different interventions the three different scenarios have been compared, i.e. before inauguration, after the inauguration with infrastructural interventions (reference scenario) and the intervention scenario. 


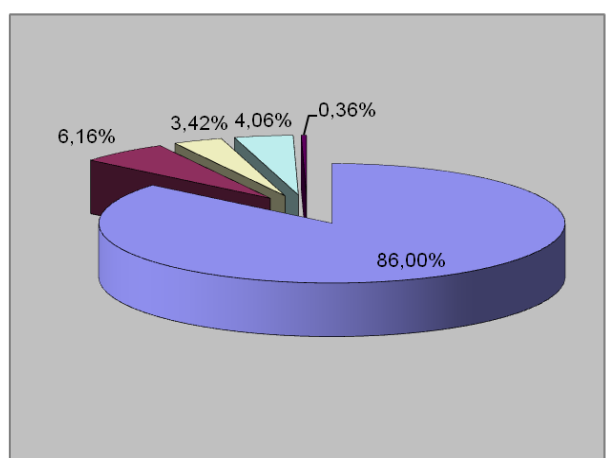

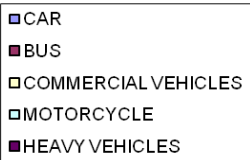

Fig. (6). Percentage of counted vehicles. Source: Authors'elaboration.

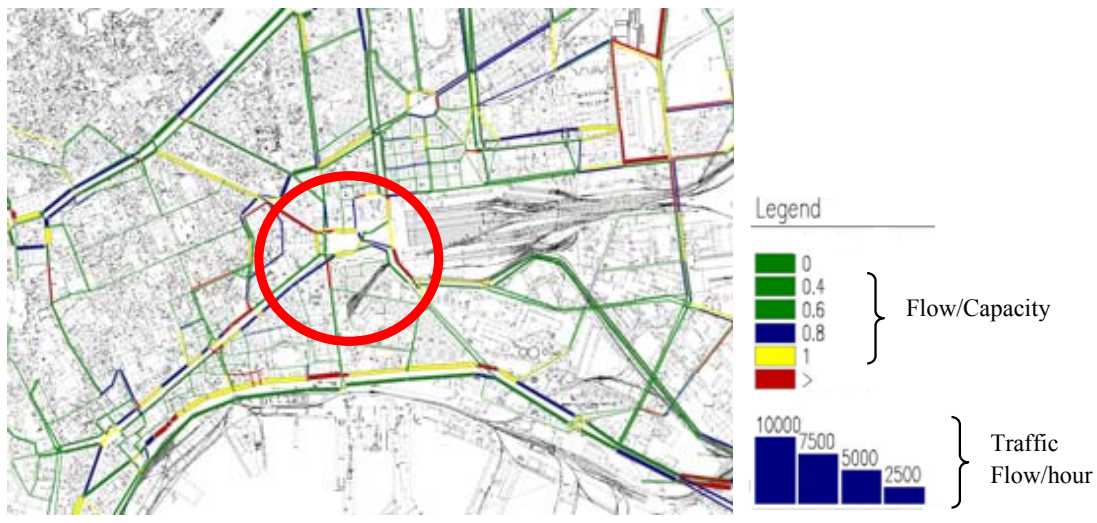

Fig. (7). Flows in garibaldi square - September 2012. Source: T-Model results.

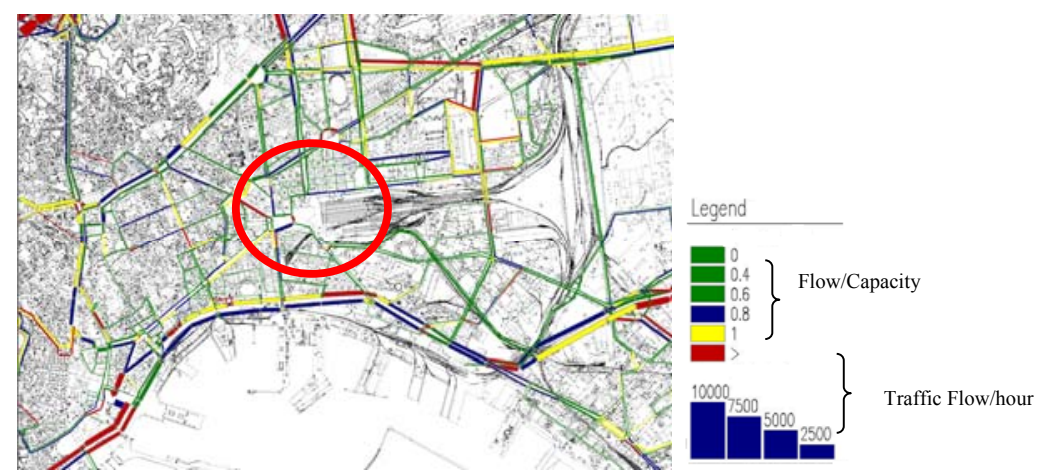

Fig. (8). Flows in garibaldi square in December 2013 with traffic's device. Source: T-Model results.

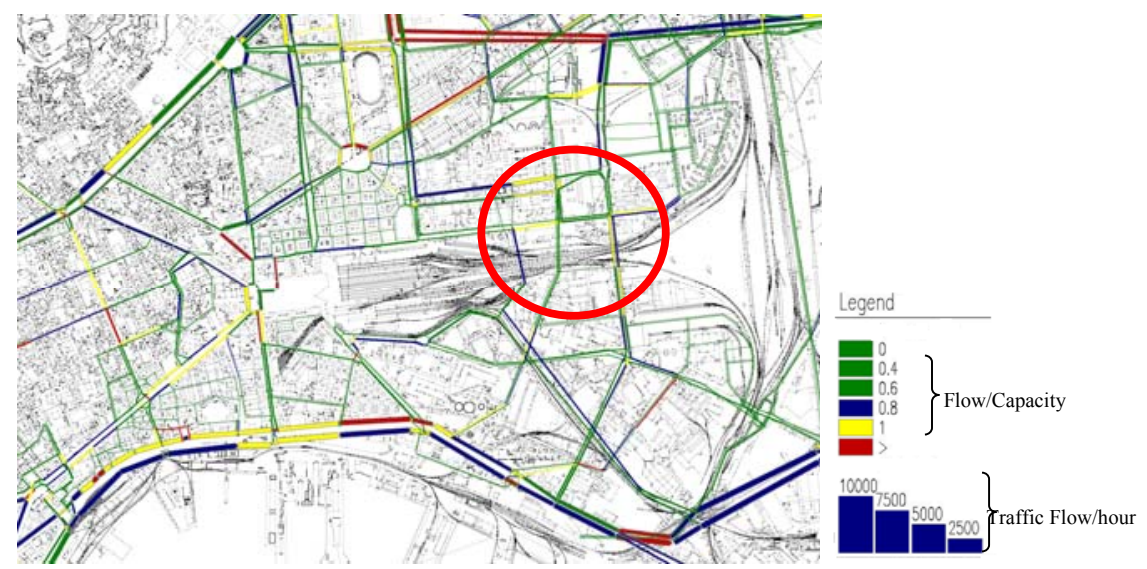

Fig. (9). Flows in garibaldi square in the future scenario with a limited traffic zone and two underpasses circled in red. Source: T-Model results. 
Table 2. Comparison among indicators (absolute values).

\begin{tabular}{|c|c|c|c|}
\hline & Before Garibaldi Station Inaguration & After Garibaldi Station Inaguration & Intervention Scenario \\
\hline \hline Performance Indicators & $\mathbf{2 0 1 2}$ & $\mathbf{2 0 1 4}$ & $\mathbf{8 1 2 9 4 0}$ \\
\hline Tot Km & $\mathbf{7 8 2 0 1 6}$ & 429548 & $\mathbf{7 9 7 4 2 0}$ \\
\hline Motorways & 420015 & 383392 & 370208 \\
\hline Other roads & 362001 & $\mathbf{4 7 2 1 2}$ & $\mathbf{4 2 2 1 8}$ \\
\hline Total time spent & $\mathbf{3 6 7 1 6}$ & 10699 & 10631 \\
\hline Motorways & 11242 & 36513 & 31587 \\
\hline Other roads & 25474 & $\mathbf{1 7 , 2 2}$ & $\mathbf{1 8 , 8 9}$ \\
\hline Average speed (Km/h) & $\mathbf{2 1 , 3 0}$ & 40,15 & 10,50 \\
\hline Motorways & 37,36 & 14,21 & 40,19 \\
\hline Other roads & & 11,72 \\
\hline
\end{tabular}

Table 3. Comparison among indicators (absolute values and \% values).

\begin{tabular}{|l|r|r|r|c|}
\hline \multirow{2}{*}{ Performance Indicators } & \multicolumn{2}{|c|}{ Absolute Variation } & \multicolumn{2}{c|}{ \% Variation } \\
\cline { 2 - 5 } & $\mathbf{2 0 1 4 - 2 0 1 2}$ & Intervention Scenario-2014 & $\mathbf{2 0 1 4 - 2 0 1 2}$ & Intervention Scenario-2014 \\
\hline \hline Tot Km & $\mathbf{3 0 9 2 4}$ & $\mathbf{- 1 5 5 2 0}$ & $\mathbf{3 , 9 5 \%}$ & $\mathbf{- 1 , 9 1 \%}$ \\
\hline Urban motorways & 9533 & -2336 & $\mathbf{2 , 2 7 \%}$ & $\mathbf{- 0 , 5 4 \%}$ \\
\hline Other roads & 21391 & -13184 & $\mathbf{5 , 9 1 \%}$ & $\mathbf{- 3 , 4 4 \%}$ \\
\hline Total time spent & $\mathbf{1 0 4 9 6}$ & $\mathbf{- 4 9 9 4}$ & $\mathbf{2 8 , 5 9 \%}$ & $\mathbf{- 1 0 , 5 8 \%}$ \\
\hline Urban motorways & -543 & -68 & $\mathbf{- 4 , 8 3 \%}$ & $\mathbf{- 0 , 6 4 \%}$ \\
\hline Other roads & 11039 & -4926 & $\mathbf{4 3 , 3 3 \%}$ & $\mathbf{- 1 3 , 4 9 \%}$ \\
\hline Average speed (Km/h) & & $\mathbf{- 1 9 , 1 6 \%}$ & $\mathbf{9 , 6 9 \%}$ \\
\hline Urban motorways & & $\mathbf{7 , 4 6 \%}$ & $\mathbf{0 , 0 9 \%}$ \\
\hline Other roads & & $\mathbf{- 4 , 8 1 \%}$ & $\mathbf{0 , 4 7 \%}$ \\
\hline
\end{tabular}

The before inauguration scenario refers to the year 2012; the reference scenario refers to February 2014 after the inauguration of the metro station Garibaldi and the intervention, limiting cars crossing the square from the north to the south. The intervention scenario considers the two underpasses.

The indicators computed and referred to the system simulated in the peak morning period are:

1. Total $\mathrm{km}$ on the network (flow * link length)

2. Total time spent (flow * link travel time)

3. Average speed (total $\mathrm{km} /$ total time spent)

The comparison has been considered for different roads typology.

From the analysis of the results reported in Tables 2 and 3, reporting the absolute value and the absolute and percentage change respectively, it results, by comparing the indicators of the before inauguration scenario (2012) and those of the reference scenario (2014), an increase of $2 \%$ of $\mathrm{km}$ travelled on the motorway network and an increase of almost $6 \%$ on other roads. An increase of $4 \%$ is registered in the total of $\mathrm{km}$ travelled. The greatest increase is registered in the $\mathrm{km}$ of other types of roads following the interventions of limiting the cars. Indeed users are pushed to choose other roads for reaching the different destinations close the Garibaldi node.

It is also true that the year 2012 was an year of crisis and that the flows on the network resulted to be extremely less. This is confirmed by the increase of $43 \%$ of the total time spent on other roads, linked to the high traffic flow on these roads. Concerning the time spent on urban roads it is possible to notice a reduction of almost $5 \%$. Finally, by comparing the average speed it is possible to highlight a reduction on the entire network equal to $19 \%$.

In conclusions the analysis of the indicators of the two scenarios confirms the speed decrease, with still "points" of local congestion, determining an increase of the total time spent on the network. There are weaknesses within the road network and therefore interventions are needed in order to reduce the load and making the general state of the network working better.

By comparing the future scenario with the reference one (i.e. 2014), it is possible to observe that for the total $\mathrm{km}$ on the motorways the difference is less than $1 \%$. An increase of 
$3 \%$ is registered on the total $\mathrm{km}$ on the other roads. The percentage decrease is due to the opening of the two underpasses and the limitation of the cars. Also from the total time spent it is possible to notice a reduction equal to $10 \%$. On the other roads the decrease is equal to $13 \%$.

Through the comparison of the average speeds, the change is really insignificant both on motorways and on other roads.

In conclusions in the future infrastructural scenario, i.e. with the opening of the two underpasses, will allow the redistribution of traffic flows making a satisfactory level of functioning of the entire network.

\section{CONFLICT OF INTEREST}

The authors confirm that this article content has no conflict of interest.

\section{ACKNOWLEDGEMENTS}

Declared none.

\section{REFERENCES}

[1] E. Cascetta, Transportation Systems Analysis. Models and Applications. Springer, New York, 2009.

[2] F. Pagliara, and E. Papa, "Urban rail systems investments: an analysis of the impacts on property values and residents' location", Journal of Transport Geography, vol. 19, pp. 200-211, 2011.

[3] E. Cascetta, and F. Pagliara, "The regional metro system project of Naples and Campania", Transport Policy, vol. 15, no. 2, pp. 81-93, 2008.

[4] E. Cascetta, A. Cartenì, F. Pagliara, and M. Montanino, "A new look at planning and designing transportation systems. Part II: A decision-making model based on cognitive rationality, stakeholders engagement and quantitative methods", Transport Policy, vol. 38, pp. 27-39, 2015.

[5] E. Cascetta, A. Papola, F. Pagliara, and V. Marzano, "Analysis of mobility impacts of the high speed Rome-Naples rail link using withinday dynamic mode service choice models", Journal of Transport Geography, vol. 19, pp. 635-643, 2011. 